\title{
Optical Performance and Optimization of Two Stationary Compound Parabolic Collectors (CPC)
}

\author{
Evangelos Bellos, Christos Tzivanidis, Kimon A. Antonopoulos \\ National Technical University of Athens/ School of Mechanical Engineering \\ Heroon Polytechniou 9, Zografou-Athens, Greece \\ bellose@central.ntua.gr; ctzivan@central.ntua.gr; kanton@central.ntua.gr
}

\begin{abstract}
Solar energy utilization is very important for our society in order to reduce the environmental problems. Solar collectors are the heat exchanger devices which capture the solar energy and produce useful heat from this. In this study, two stationary compound parabolic collectors with tubular receivers are optimized and compared in order to determine the most suitable solution for yearly utilization. The fist cpc uses one reflector in order to concentrate the solar rays to the receiver and the other uses two reflectors in order to follow the solar position during the year. The shape of every reflector is parametrized with Bezier-Bernstein polynomials in order to optimize them. The reflectors are stationary without tracking in order to reduce the cost of them and to have a simple and lowcost technology. A typical day for every month is analyzed in order to cover all the year period and the total analysis is made with Solidworks flow simulations studio. The collectors are located in Athens with latitude $38^{\circ}$ and they are placed with zero azimuth angles in order to be turned in the south direction. The final results are evaluated yearly and monthly by comparing the energy that is delivered to the tubular receiver. The single reflector performs $3.2 \%$ better than the double, but the double gives a better distribution among the months. So the most suitable solution is the cpc with the double reflector in order to produce useful heat in all months with a similar way.
\end{abstract}

Keywords: CPC, Bezier, optical performance, reflector, optimization

\section{Introduction}

The role of energy becomes increasingly important to fulfil needs of modern societies and to follow the fast economic and industrial growth worldwide $[1,2]$. The increasing cost of fossil fuels and of the electricity combined with the global warming problem caused by the $\mathrm{CO}_{2}$ emissions lead our society to turn in renewable energy sources. Solar energy is the oldest energy source ever used and is a very promising source to cover a great part of worldwide energy demand by various ways. Moreover, solar radiation has the highest availability and the lowest replenishment time [3, 4] which make the mist suitable renewable energy source. Many applications utilize solar energy from industrial hot water supply to electricity production [4, 5], especially with high radiation levels as Greece [7, 8].

Solar collectors are the devices which capture the solar energy and convert it to useful heat. For low temperature level $\left(<90^{\circ} \mathrm{C}\right)$, flat plate collectors are the most suitable solution with a low cost. For greater temperature levels (100$150^{\circ} \mathrm{C}$ ) evacuated tubes are the ideal solutions because these collectors have high thermal efficiency [9]. A simple way to increase the efficiency is to use a reflector to concentrate the energy to the reflector. This technology leads to higher operation temperature level with great efficiency. For low concentration ratio $(<5)$ the collectors are no-imaging $(\mathrm{CPC})$, but for higher they have specific image of the sun in the receiver (PTC, Fresnel, Solar dish) [10]. For this reason a tracking system is necessary for high concentration ratios in order to have efficient reflections. In the compound parabolic collector with low concentration ratio a stationary design is a very important issue because the lack of tracking system decreases the cost of the system.

Tiba et al. [11] studied the optical and the thermal behavior of stationary cpc with low concentration ratio. The main parameter in this analysis was the acceptance angle and the concentration ratio. Ratismith et al. [12] compared two nontracking compound parabolic collectors with evacuated tubes, the first with horizontal flat pate absorber and the second with vertical one and concluded that the two systems have a daily performance of about $40 \%$. Kim et al. [13] studied stationary cpc collectors with their axis in North-South and East-West direction by using different geometries in every case. The collector in the N-S direction performed better, but it had a lower concentration ratio something that equalizes 
the comparison between the collectors. Umair et al. [14] studied a stationary CPC with wings angled toward the east and west in order to have great efficiency during the day. In this study the titled angle of the cpc parts was investigated in order to optimize the collector and the final results showed better performance than the respect linear collector. Souliotis and Tripanagnostopoulos have investigated the performance of stationary asymmetric cpc in Greece for heating water [15-18]. Su et al [19] made a comparison of a novel lens-walled compound parabolic concentrator (lens-walled CPC) with the common mirror and dielectric solid CPCs for yearly utilization.

In this study two different compound parabolic collectors with tubular receivers are analyzed and optimized for yearly operation in Athens. The first one consists of a typical reflector and the other one is constructed by two reflectors (double reflector). The slope of these reflectors is the factor that changes their yearly performance. The exact geometry of every reflector is parametrized by Bezier-Bernstein polynomials in order to control the geometry by an easy way. The geometry with the greater optical performance is selected as the optimum in every case. Another important parameter is the variation of the optical performance during the year, with a uniform distribution to be preferable. The models are simulated in Solidworks flow simulation which gives many features to the users for solar utilization applications.

\section{Examined models and Methodology}

\subsection{Examined models}

Two different compound parabolic collectors are investigated in this analysis and optimized in order to predict the more suitable solution for yearly performance. The first one has a single reflector and the other a double. The typical stationary cpc, the single reflector, is located with their axis in East-West direction and with a slope. The optimum slope for yearly use is equal to latitude of the place that the collector is located. In this case, Athens with latitude of $38^{\circ}$ leads us to set the slope in this value [20]. The problem from this design is that the collector performs extremely well the periods close to equinoxes and the other periods have a low efficiency. In order to face this problem a double reflector collector is investigated with one reflector designed for summer and the other for winter. More specifically the summer reflector has a lower slope $\left(20^{\circ}\right)$ and the winter a greater $\left(56^{\circ}\right)$, a design that tries to follow the sun in the respective period. The sun altitude is greater in the summer than the winter which leads the optimum slope of the collector to be lower in the summer and greater in the winter. The next figure presents the two collectors with the main dimensions:
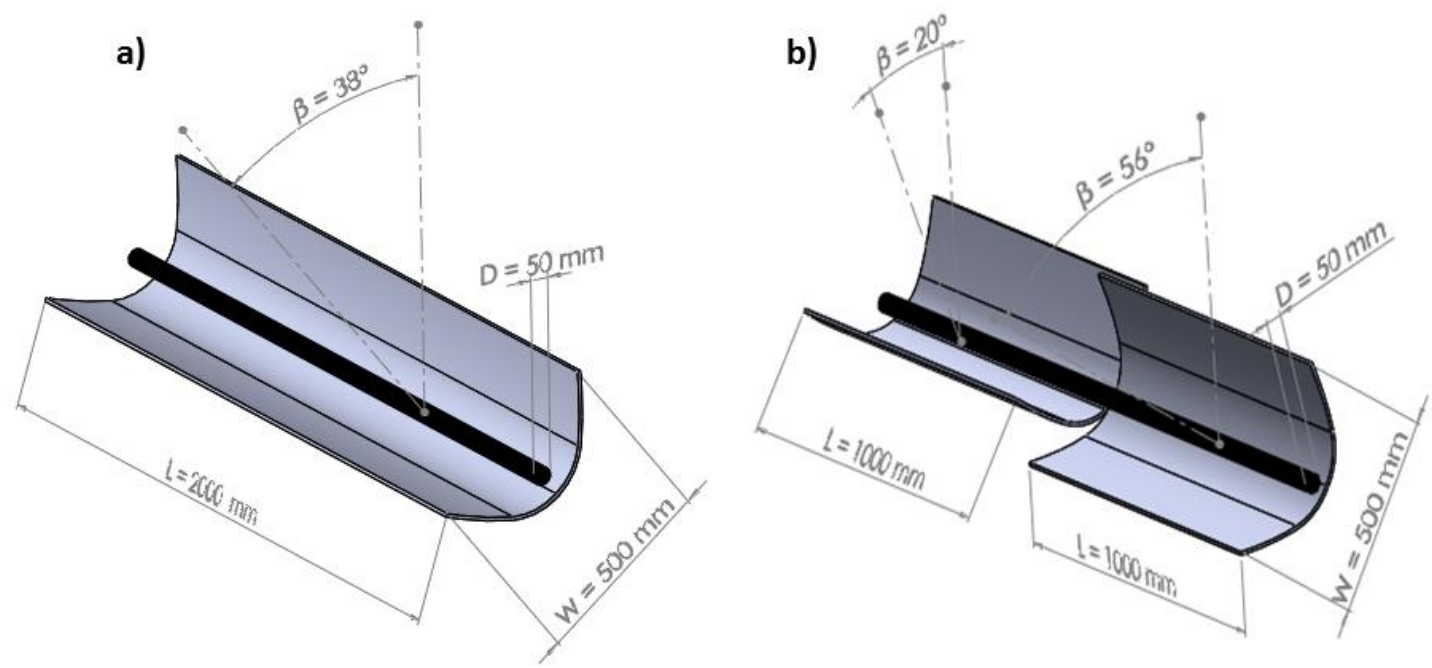

Fig. 1: CPC models and their dimensions. a) The single cpc, b) The double cpc.

It is important to state that the azimuth of collector surfaces is zero which means that the collectors are turned to the south direction. The receiver is tubular with diameter $50 \mathrm{~mm}$ while the aperture is constant at $500 \mathrm{~mm}$ in all cases. The concentration ratio can be calculated as: 


$$
C=\frac{A_{a}}{A_{r}}=\frac{W \cdot L}{\pi \cdot D \cdot L}=\frac{500}{\pi \cdot 50} \approx 3.183
$$

This value is realistic for a cpc, because the typical values are between 1 and 5 [20]. The reflector in this analysis is ideal and the reflectance losses are negligible. This hypothesis does not influence on the comparison between the two collectors so it is acceptable.

\subsection{Design cpc shape}

The reflector of the collector has two parabolic parts and one other which connect them. In this case the parabolic parts are same, so the collector is symmetrical. A Bezier parametrization of the parabolic parts takes place in this study in order to control the parabolic geometry. The Bezier polynomial creates a parametric curve which is controlled by the position of some points, the control points. The degree of the polynomial is one lower than the number of the points. The parabolic shape of the curve need a second degree polynomial, so 3 control points are used in order to create a parabolic curve. The first and the last point are stable in this method, with the intermediate point to be moved by changing the geometry. The coordinates of this point $(\mathrm{X}, \mathrm{Y})$ are the optimization parameters of the problem.

The main dimensions of the model are the parabola height $(\mathrm{H})$, the down part height $(\mathrm{h})$, the aperture width $(\mathrm{W})$, the half-acceptance angle of the collector $\left(\Theta_{c}\right)$, the bottom distance $(B)$ and the receiver diameter (D) are presented. These parameters remain constant for all cases. The down part has cyclical geometry and also remains constant in all cases. The tubular receiver is approximately tangent to the lines which is presented on figure 2 . This relationship is optimum because makes all the reflected rays to arrive in the receiver when the sun rays are vertical to the aperture. The next table gives all the useful dimensions and information of the model.

Table 1: Dimensions of the model.

\begin{tabular}{|l|l|l|l|}
\hline Parameter & Value & Parameter & Value \\
\hline Aperture (A) & $1 \mathrm{~m}^{2}$ & $\Phi$ & $38^{\circ}$ \\
\hline Length (L) & $2 \mathrm{~m}$ & Concentration ratio $(\mathrm{C})$ & 3.183 \\
\hline Width $(\mathrm{W})$ & $0.5 \mathrm{~m}$ & Half-acceptance angle $\left(\Theta_{\mathrm{C}}\right)$ & $67.4^{\circ}$ \\
\hline Receiver diameter $(\mathrm{D})$ & $0.05 \mathrm{~m}$ & Bottom distance $(\mathrm{B})$ & $0.25 \mathrm{~m}$ \\
\hline Parabola Height $(\mathrm{H})$ & $0.15625 \mathrm{~m}$ & Bottom Height $(\mathrm{h})$ & $0.05 \mathrm{~m}$ \\
\hline
\end{tabular}

The next figure shows the cpc geometry with the dimensions which are constant for all cases. Additionally, the way that the control point position influences on the parabolic shape is presented by an extra example (blue line) in the following figure:

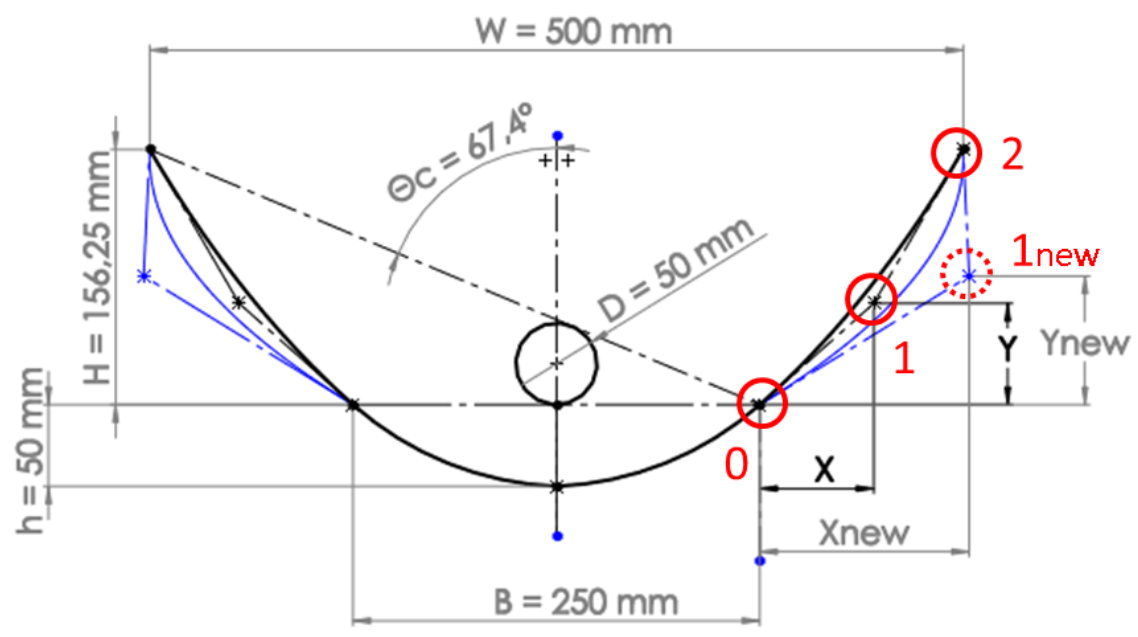

Fig. 2: CPC geometry and Bezier parametrization. 
The parabolic part is the part which changes and is controlled by the point (1). The total curve is determined by the position of points (0), (1) and (2). Points (0) and (2) remain constant but point (1) changes position by moving the parabolic part close to it. In the above figure it obvious that the movement of the point 1 to 1 new makes the curve to move from the black on the blue one. The Bezier curve is given by a dimensionless parameter ( $\mathrm{t}$ ) which takes values from 0 (point 0) to 1 (point 2). An intermediate value of this parameter leads to an intermediate point of the curve. The general equation of the curve is given from the next equation:

$$
\vec{r}(t)=\sum_{i=0}^{N}\left(\vec{r}_{i} \cdot g_{i}^{N}(t)\right)
$$

Where $r$ is the position vector of the curve points and $r_{i}$ the position vector of the control points which are $N+1$. So in this case, $\mathrm{N}=2$ because there are 3 control points in order to have a parabolic shape. The coefficient $\mathrm{g}$ is calculated from the next equation:

$$
g_{i}^{N}(t)=\frac{N !}{i ! \cdot(N-i) !} \cdot t^{i} \cdot(1-t)^{i}
$$

For our case, the equation (2.2) is analyzed in two equations, one for $\mathrm{X}$ and one for $\mathrm{Y}$ :

$$
\begin{gathered}
X(t)=X_{0} \cdot(1-t)^{3}+X_{1} \cdot t \cdot(1-t)^{2}+X_{2} \cdot t^{3} \\
Y(t)=Y_{0} \cdot(1-t)^{3}+Y_{1} \cdot t \cdot(1-t)^{2}+Y_{2} \cdot t^{3}
\end{gathered}
$$

The coordinates of the point 0 are $(0,0)$ and of the point $2(125,156.25)$ in millimeters. The values of the point 1 $(\mathrm{X}, \mathrm{Y})$ is located in an area and the optimum position of it is the goal of this study.

\subsection{Methodology}

The goal is to find the optimum geometry for every reflector (single and double) and to compare them. Every collector is analyzed separately by testing different couples of the $\mathrm{X}$ and $\mathrm{Y}$ coordinates of the control point 1 . In the single reflector case, only two are the parameters of the optimization, but in double reflector the parameters are double because the two reflectors are modelled with Bezier and optimized separately. The optimum reflector is the one which gives useful energy for all over the year period and not only for some months. This criterion is realistic, because in the case that the collector performs well only for some months, a tracking system is necessary.

The collector is designed in Solidworks and is simulated in Flow Simulation Studio with time-depended analysis. The simulation takes part for 13 hours daily and for the 12 days, one typical day of every month [21]. With this way all the months are taken into consideration and the results are realistic. The output of the simulation is the hourly mean radiation which reaches to the absorber. By multiplying this value with the total simulation time (13 hours) the daily total energy in the collector is calculated. In order to have realistic results the monthly cloudless is taken into consideration by importing it in the general settings of the simulation. The calculation of mean monthly cloudiness has been made by data for Athens [8]. The latitude of Athens $\left(\varphi=38^{\circ}\right)$ and the exact date in every case are also selected in the general settings. Empirical relations for the solar radiation are used by Solidworks and the final solar energy is calculated in every moment.

\section{Results}

In this paragraph the final results of the simulations are presented. First of all the optimum geometries are presented. It is important to state that the same geometry was the optimum one for the two reflectors of the double reflector. The next scheme shows the different of the parabolic parts for the single and the double reflector. 


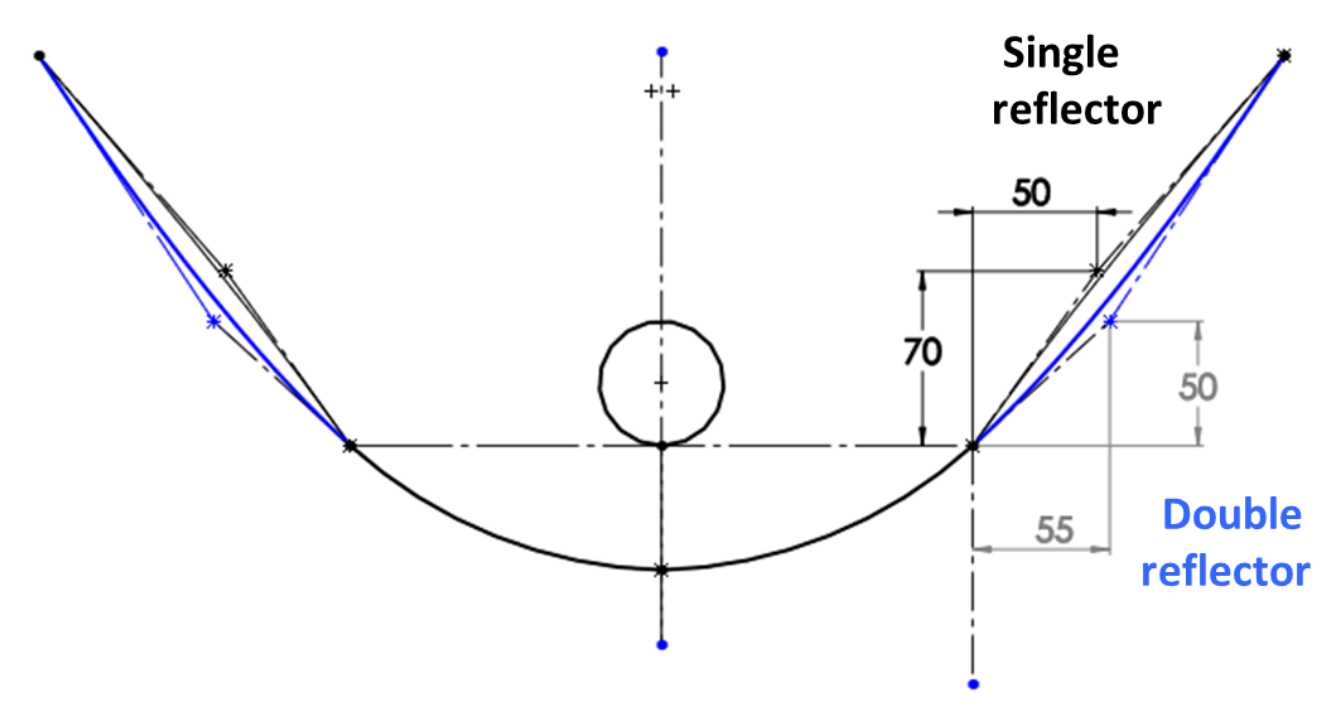

Fig. 3: Optimum geometries for the single and double reflector.

It is obvious that the two optimum geometries are different to each other, with the parabolic part in the single reflector to be close to line. More specifically, the two parabolic parts have different curvatures, something very interesting. In the case of the double reflector, every part is designed to receive the solar energy with small incidence angles which lead the geometry close to ideal parabola. In the single reflector, the solar angle reaches to the reflector with various incident angles which makes the parabolic shape not very effective. So a different shape, closer to line is proved as the optimum one. The following table gives the daily energy delivered to the absorber for all the months for the two cases:

Table 2: Daily and yearly energy delivered to the receiver.

\begin{tabular}{|l|l|l|l|l|}
\hline \multirow{2}{*}{ Month } & \multirow{2}{*}{ Mean Day } & \multirow{2}{*}{ Mean $\mathrm{K}_{\mathrm{T}}$} & $\mathrm{H}\left(\mathrm{kWh} / \mathrm{m}^{2}\right)$ & \\
\cline { 4 - 5 } & & & Single reflector & Double reflector \\
\hline January & 17 & 0.423 & 0.722 & 1.086 \\
\hline February & 16 & 0.480 & 1.710 & 1.818 \\
\hline March & 16 & 0.542 & 2.961 & 1.462 \\
\hline April & 15 & 0.602 & 2.831 & 2.186 \\
\hline May & 15 & 0.642 & 1.598 & 2.210 \\
\hline June & 11 & 0.671 & 1.097 & 1.904 \\
\hline July & 17 & 0.700 & 1.364 & 2.192 \\
\hline August & 16 & 0.694 & 2.560 & 2.667 \\
\hline September & 15 & 0.643 & 3.587 & 1.783 \\
\hline October & 15 & 0.559 & 2.492 & 2.179 \\
\hline November & 14 & 0.473 & 1.025 & 1.343 \\
\hline December & 10 & 0.419 & 0.569 & 0.955 \\
\hline \multicolumn{2}{|l}{ Yearly Energy $\left(\mathrm{kWh} / \mathrm{m}^{2}\right)$} & & 684.33 & 662.70 \\
\hline
\end{tabular}

From the above table it is obvious that the yearly energy utilization is similar for the two collectors with the single reflector collector perform $684 \mathrm{kWh} / \mathrm{m}^{2}$ and the double $663 \mathrm{kWh} / \mathrm{m}^{2}$. By evaluating them with this criterion the single reflector is the more suitable solution. The next diagram gives extra information, by presenting the energy deviation during the year: 


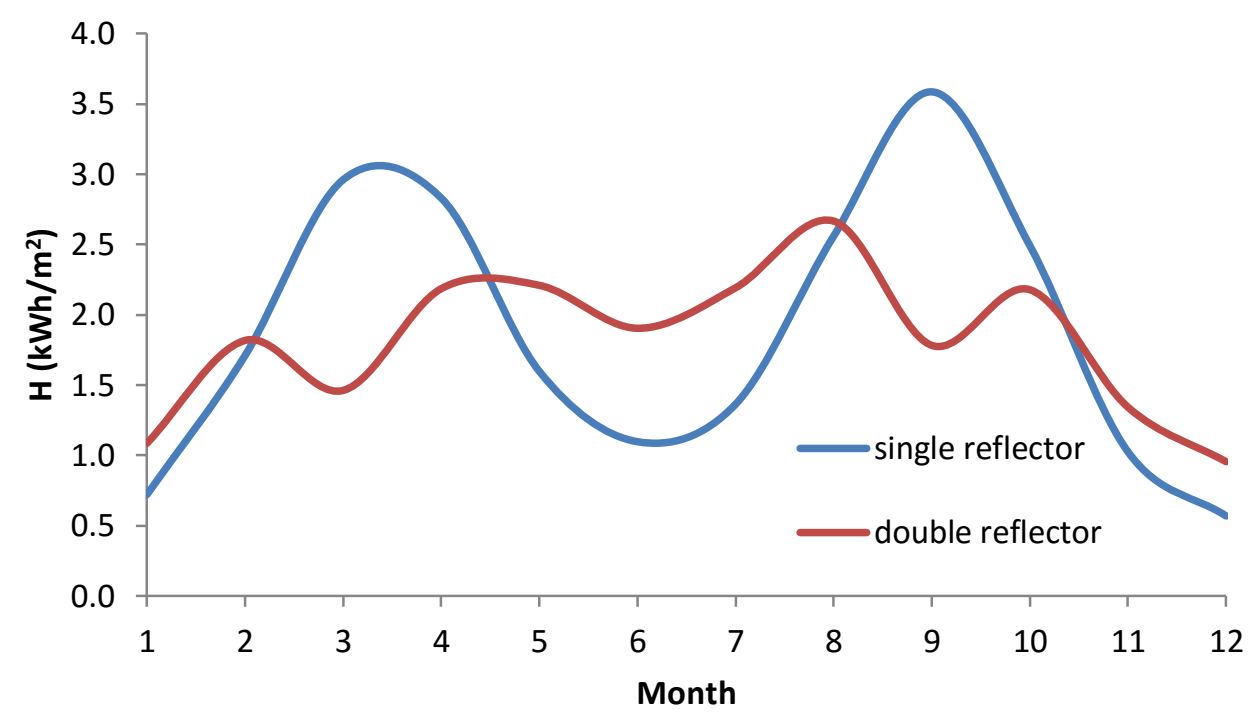

Fig. 4: Energy delivered to the receiver during the year. With blue color the single reflector and with red color the double.

The energy production with the single collector varies a lot during the year with the maximum values at March and September when the sun rays are approximately vertical to the collector aperture at the noon. In the double collector a more constant energy distribution is observed. This is very important because the double reflector is able to drive the collector all the months efficiently and this is preferable. The double reflector performs better the periods far from equinoxes because in these periods the single reflector is very efficient.

Table 3: Mean and maximum radiation of the typical day for all the months.

\begin{tabular}{|l|l|l|l|l|l|}
\hline \multirow{2}{*}{ Month } & \multicolumn{2}{l}{ Single reflector } & Double reflector & \multirow{2}{*}{ Best solution } \\
\cline { 2 - 6 } & Mean I $\left(\mathrm{W} / \mathrm{m}^{2}\right)$ & Max I $\left(\mathrm{W} / \mathrm{m}^{2}\right)$ & Mean I $\left(\mathrm{W} / \mathrm{m}^{2}\right)$ & Max I $\left(\mathrm{W} / \mathrm{m}^{2}\right)$ & \\
\hline January & 56 & 146 & 84 & 196 & Double \\
\hline February & 132 & 423 & 112 & 286 & Double \\
\hline March & 228 & 419 & 168 & 189 & Single \\
\hline April & 218 & 300 & 170 & 291 & Single \\
\hline May & 123 & 189 & 146 & 364 & Double \\
\hline June & 84 & 252 & 168 & 325 & Double \\
\hline July & 106 & 435 & 205 & 375 & Double \\
\hline August & 197 & 505 & 137 & 386 & Double \\
\hline September & 276 & 397 & 167 & 227 & Single \\
\hline October & 192 & 206 & 92 & 311 & Single \\
\hline November & 79 & 110 & 65 & 240 & Double \\
\hline December & 39 & & & 176 & Double \\
\hline
\end{tabular}

From table 3 it is obvious that the double reflector performs better for more months than the single reflector, by using the criterion of mean hourly radiation I for every month. Moreover, the above table shows that the maximum daily radiation, which is observed in the solar noon, is about 2.5 greater than the mean daily radiation delivered to the receiver. The next figure gives the exact radiation profile for all the typical days of the year. 

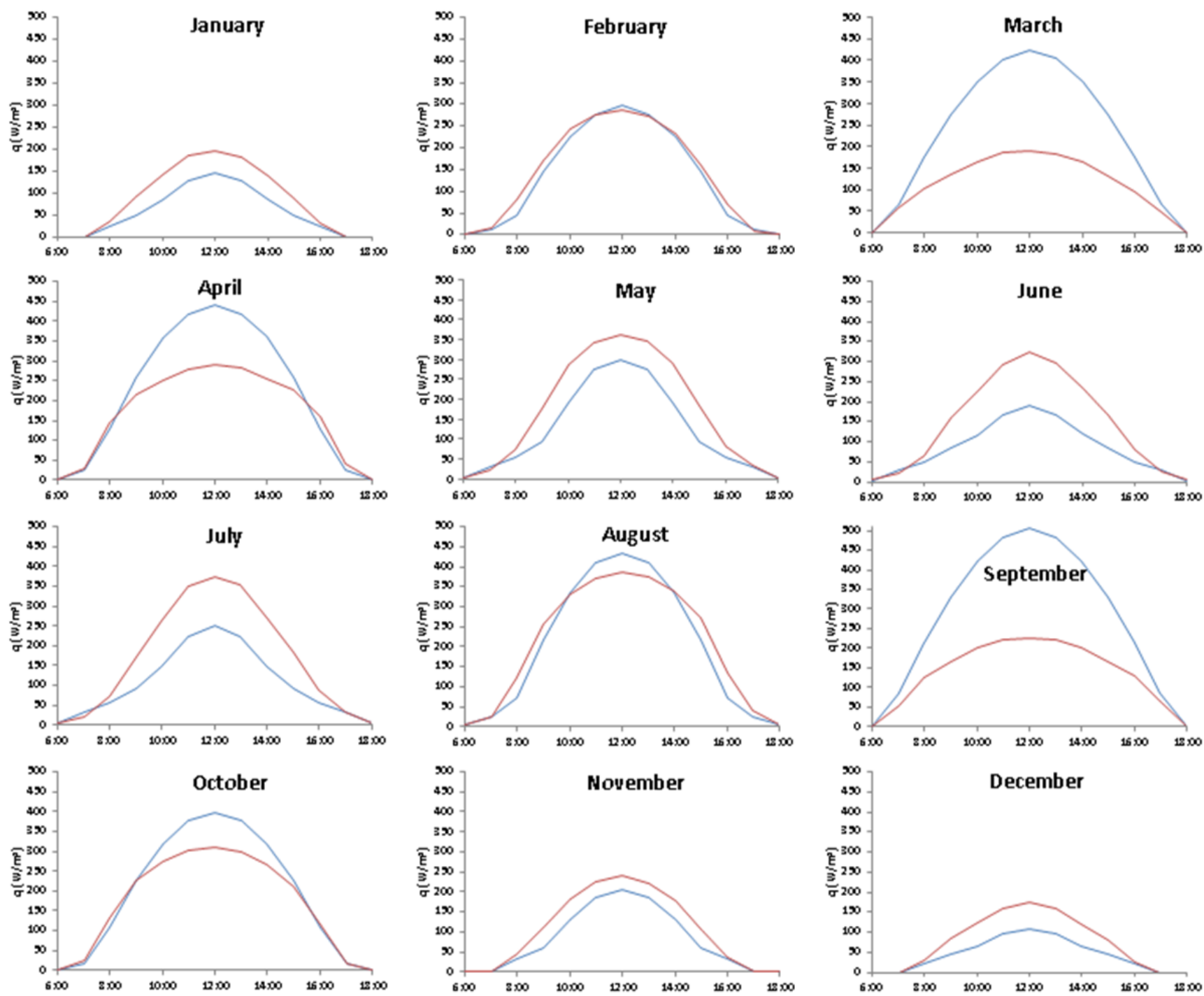

Fig. 5: Specific Radiation distribution during the typical day for every month. With blue line the single reflector and with the red the double reflector.

Figure 5 presents the specific radiation in the receiver during the day for all months. The blue line presents the case with one reflector and the red with the double one. The shape of the curves is similar in all cases with the maximum value is observed in the solar-noon. The double reflector performs better more months than the single, fact that makes this reflector the most suitable solution by taking into consideration the demand for a uniform profile.

\section{Conclusions}

In this study the yearly performance of two different cpc collectors are investigated in order to predict the suitable reflector for yearly utilization. Every collector shape is optimized by Bezier parametrization. Especially the parabolic part of every collector is the part which affects the reflection, so it is optimized by changing the position of a control point. The final results show that different geometries are the optimum for the different reflectors. In the single reflector with a slope at $38^{\circ}$ the optimum geometry is close to line, but in the case with the double reflector a classic parabolic shape performs better. By comparing the two collectors, the single reflector gives 3.2\% greater energy to the receiver by accounting all the months. But the energy distribution of this case is non-uniform because this reflector performs well close to equinoxes. So a more detailed analysis was presented by comparing monthly the two collectors. The final comparison showed that the 
double collector gives a more uniform distribution and is more efficient in 8 months. This leads us to select the double reflector as the optimum solution, for applications that utilize the solar energy in yearly bases. The single reflector performs better the months March, April, September and October and is ideal for applications which need more energy these months.

\section{References}

[1] E. Bellos, C. Tzivanidis, D. Korres, and K. A. Antonopoulos, "Thermal analysis of a flat plate collector with Solidworks and determination of convection heat coefficient between water and absorber," in Proceedings of the ECOS Conference, Pau, France, 2015.

[2] F. A. Al-Sulaiman, I. Dincer, and F. Hamdullahpur, "Energy and exergy analyses of a biomass trigeneration system using an organic Rankine cycle," Energy, vol. 45, pp. 975-985, 2012.

[3] W. A. Hermann, "Quantifying global exergy resources," Energy, vol. 31, pp. 1685-1702, 2006.

[4] D. N. Nkwetta, M. Smyth, A. Zacharopoulos, and T. Hyde, "Optical evaluation and analysis of an internal lowconcentrated evacuated tube heat pipe solar collector for powering solar air conditioning systems," Renewable Energy, vol. 39, pp. 65-70, 2012.

[5] N. S. Suresh, N. C. Thirumalai, B. S. Rao, and M. A. Ramaswamy, "Methodology for sizing the solar field for parabolic trough technology with thermal storage and hybridization," Solar Energy, vol. 110, pp. 247-259, 2014.

[6] A. Fernández-García, E. Zarza, L. Valenzuela, and M. Pérez, "Parabolic-trough solar collectors and their applications," Renewable Sustainable Energy Reviews, vol. 14, pp. 1695-721, 2010.

[7] K. Zabara, "Estimation of the global solar radiation in Greece," Solar \& Wind Technology, vol. 3, no. 4, pp. 267-272, 1986.

[8] D. A. Kouremenos, K. A. Antonopoulos, and S. Doulgerakis, "Direct and diffuse solar radiation correlations for tilted surfaces in Athens, Greece," Solar Energy, vol. 38, no. 3, pp. 203-217, 1987.

[9] E. Bellos, C. Tzivanidis, and K. A. Antonopoulos, "Thermal performance of a direct-flow coaxial evacuated tube with solidworks flow simulation," in Proceedings of the $6^{\text {th }}$ International Conference on Experiments/Process/System Modelling/Simulation/Optimization, Athens, Greece, 2005, pp. 8-11.

[10] S. Kalogirou, “Solar Energy Engineering,” S. A. Kalogirou, Ed. Boston: Academic Press, 2009.

[11] C. Tíba and N. Fraidenraich, "Optical and thermal optimization of stationary non-evacuated CPC solar concentrator with fully illuminated wedge receivers," Renewable Energy, vol. 36, pp. 2547-2553, 2011.

[12] W. Ratismith, A. Inthongkhum, and J. Briggs, "Two non-tracking solar collectors: Design criteria and performance Analysis," Applied Energy, vol. 131, pp. 201-210, 2014.

[13] Y. S. Kim, K. Balkoski, L. Jiang, and R. Winston, "Efficient stationary solar thermal collector systems operating at a medium-temperature range," Applied Energy, vol. 111, pp. 1071-1079, 2013.

[14] M. Umair, A. Akisawa, and Y. Ueda, "Optimum Settings for a Compound Parabolic Concentrator with Wings Providing Increased Duration of Effective Temperature for Solar-Driven Systems: A Case Study for Tokyo," Energies, vol. 7, pp. 28-42, 2014.

[15] M. Souliotis, P. Quinlan, M. Smyth, Y. Tripanagnostopoulos, A. Zacharopoulos, M. Ramirez, and P. Yianoulis, "Heat retaining integrated collector storage solar water heater with asymmetric CPC reflector," Solar Energy, vol. 85, no. 10, pp. 2474-2487, 2011.

[16] M. Souliotis and Y. Tripanagnostopoulos, "Experimental study of CPC type ICS solar systems," Solar Energy, vol. 76, no. 4, pp. 389-408, 2004.

[17] Y. Tripanagnostopoulos, P. Yianoulis, S. Papaefthimiou, M. Souliotis, and T. Nousia, "Cost effective asymmetric CPC solar collectors," Renewable Energy, vol. 16, no. 1-4, pp. 628-631, 1999.

[18] M. Souliotis and Y. Tripanagnostopoulos, "Study of the distribution of the absorbed solar radiation on the performance of a CPC-type ICS water heater," Renewable Energy, vol. 33, no. 5, pp. 846-858, 2008.

[19] Y. Su, S. B. Riffat, and G. Pei, "Comparative study on annual solar energy collection of a novel lens-walled compound parabolic concentrator (lens-walled CPC)," Sustainable Cities and Society, vol. 4, pp. 35-40, 2012.

[20] S. Kalogirou, "The potential of solar industrial process heat applications," Applied Energy, vol. 76, no. 4, pp. 337-361, 2003

[21] J. A. Duffie, and W. A. Beckman, Solar Engineering of Thermal Processes (2nd ed.). New York: Wiley Interscience; 1991. 